\title{
Modeling Study of Carbonate Decomposition in LLNL's 4TU Pilot Oil Shale Retort
}

C. B. Thorsness

October 14, 1994

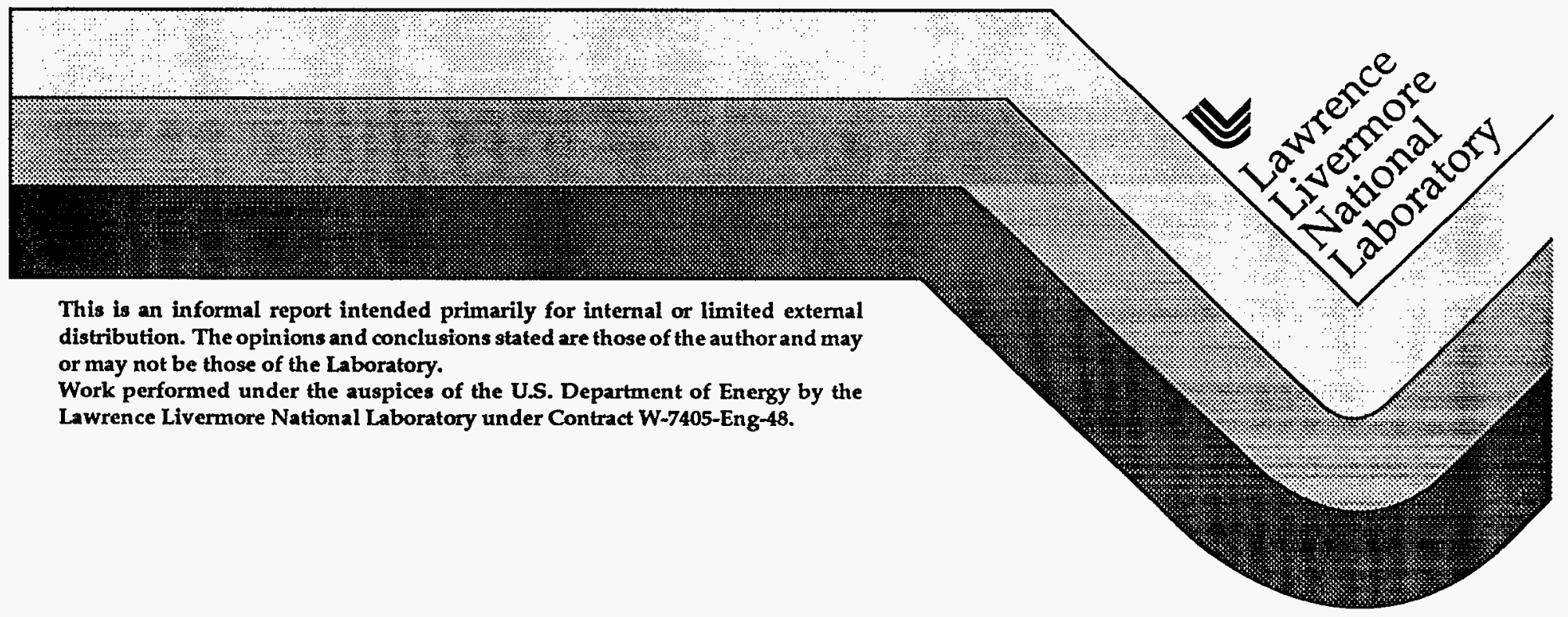


This document was prepared as an acccount of work sponsored by an agency of the United States Government. Neither the United States Government nor the University of California nor any of their employees, makes any warranty, express or implied, or assumes any legal liability or responsibility for the accuracy, completeness, or usefulness of any information, apparatus, product, or process disclosed, or represents that its use would not infringe privately own rights. Reference herein to any specific commercial products, process, or service by trade name, trademark, manufacturer, or otherwise, does not necessarily constitute or imply its endorsement, recommendation, or favoring by the United States Government or the University of California. The views and opinions of authors expressed herein do not necessarily state or reflect those of the United States Government or the University of California, and shall not be used for advertising or product endorsement purposes.

This report has been reproduced directly from the best available copy.

Available to DOE and DOE contractors from the Office of Scientific and Technical Information P.O. Box 62, Oak Ridge, TN 37831

Prices available from (615) 576-8401, FTS 626-8401

Available to the public from the National Technical Information Service

U.S. Department of Commerce 5285 Port Royal Rd., Springfield, VA 22161 


\section{DISCLAIMER}

Portions of this document may be illegible in electronic image products. Images are produced from the best available original document. 


\title{
Modeling Study of Carbonate Decomposition in LLNL's 4TU Pilot Oil Shale Retort
}

\author{
C.B. Thorsness \\ Lawrence Livermore National Laboratory \\ Livermore, California 94550
}

\begin{abstract}
$\underline{\text { Abstract }}$
Lawrence Livermore National Laboratory's (LLNL) 4 tonne-per-day oil shale Pilot Retort (4TU-Pilot) has been modeled to study the degree of carbonate decomposition occurring in the process. The modeling uses a simplified version of the processes occurring in the retort to allow parametric studies to be performed. The primary focus of the work is on the sensitivity of computed carbonate decomposition to the assumed manner in which solid material leaves the retort. It was found that for a variety of assumptions about solid passage and evolution within the process the computed carbonate decomposition varied by only a few percent. It was also determined that using available kinetic expressions based on literature data led to a consistent underestimate of the carbonate decomposition, from 12-17\% low on an absolute basis and on a relative basis as much as a factor of seven times too low. A simplified kinetic expression based on limited data from laboratory experiments on the same shale as used in the 4TU-Pilot run was also employed and found to match the pilot results fairly well.
\end{abstract}

\section{Introduction}

The large oil shale deposits of the Western United States contain significant quantities of carbonate minerals. When this shale is processed by thermal retorting to transform the organic kerogen in the shale to shale oil there is also a potential to decompose the carbonate minerals. Any decomposition of carbonate minerals associated with the shale leads to energy losses due to the endothermic nature of the reactions. In addition, the reactions produce carbon dioxide as one of the primary products and thus influences the total carbon dioxide produced per unit shale processed. Consequently, it is of interest to demonstrate the ability to estimate the degree of carbonate decomposition which will occur in a given oil shale retorting processing scheme. This report considers model results and experimental data on carbonate decomposition from LLNL's 4 tonneper-day Pilot Retort (4TU-Pilot) 1. In particular, it focuses on the range of computed results possible for a given kinetic model and a variety of assumptions related to the manner in which solids exit the process.

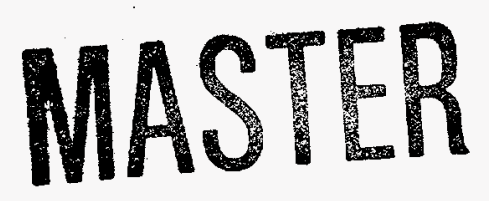




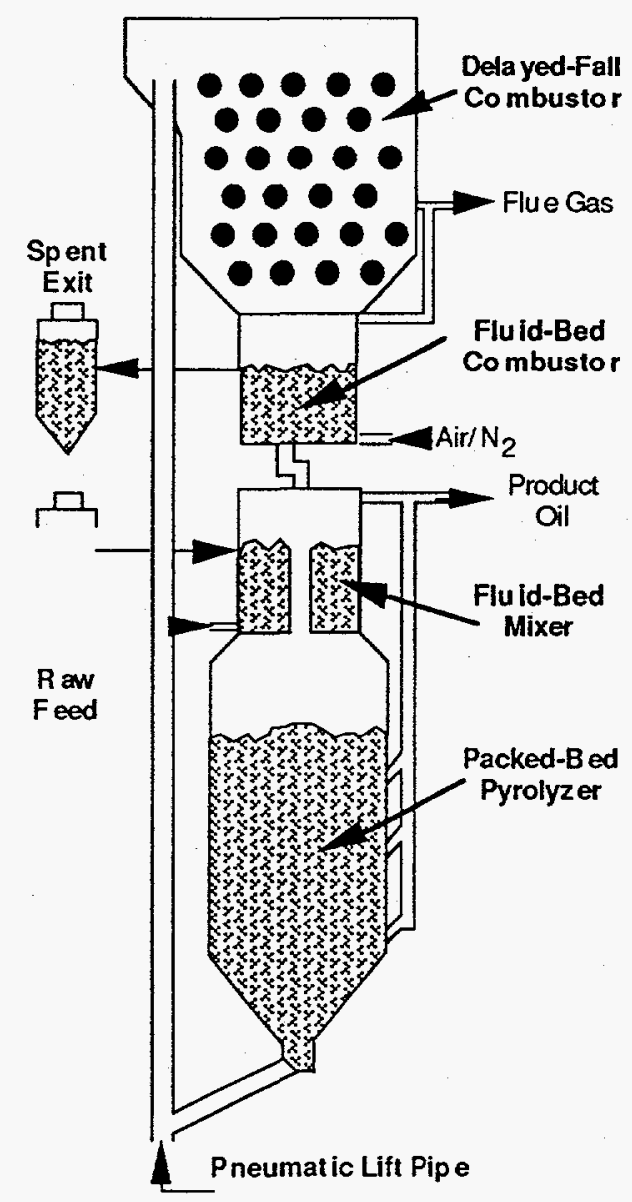

Figure 1. Schematic of the primary process units making up LLNL's 4TU-Pilot Retort.

In the 4TU-Pilot, shown schematically in Fig 1, processing begins as raw feed and recycled shale are mixed in a fluidized-bed (FBM), at a ratio of approximately 1:3. This compact unit rapidly mixes the two streams with a 30 second average solids residence time. The combined stream, leaving the mixer in thermal equilibrium at retorting temperature (approx. $500^{\circ} \mathrm{C}$ ), next spends 2-3 minutes in a gravity flow pyrolyzer (PYR), where complete pyrolysis takes place. This moving packed-bed has the advantage of uniform solid residence time and the ability to hold and process fines, which are rejected from fluidized-bed pyrolyzers. The pyrolyzer also serves as a surge tank with excess capacity to accommodate temporary process upsets. The condensable oil and gas, containing water and dust, pass through staged coolers for product recovery. After cooling, the noncondensable gas is either discharged or recycled back to fluidize the mixer. The solid leaving the pyrolyzer enters the pneumatic lift-pipe (LFT), where residual carbon on the spent shale is combusted during transport to the top of the tower. The lift discharges into a delayed-fall combustor (DFC), which provides an additional 5 -second residence time for shale combustion in a compact 2.5 meter unit. Below the DFC, the gas and solid is separated with the solid entering a fluid-bed classifier (FBC). This unit has two functions. First, it classifies the shale, discharging the smaller material into the spent shale hopper and recycling the larger shale back to the fluid-bed mixer. Second, it provides a pressure block to balance the loop, keeping separate the combustion and pyrolysis atmospheres of the process. 
Previously, calculations using LLNL's Oil Shale Process (OSP) model have been performed to analyze the results from a series of shale retorting experiments performed in LLNL's 4TU-Pilot ${ }^{2}$. The results from these calculations indicated that more carbonate was decomposing in the 4TU-Pilot runs than the OSP model results indicated should be occurring. These results are summarized in Table 1. The decomposition, as measured by change in acid evolved carbon dioxide, indicates that, depending on the test, 14 to $46 \%$ of the carbonate originally present decomposed. The model calculations yielded lower estimates in all cases. The discrepancy between model calculations and measured decomposition ranged from 9 to $23 \%$.

Table 1. OSP model calculations of carbonate decomposition for the 4TU-Pilot and results from Pilot runs for both lean (H8, 9, 10 and 14) and rich $(\mathrm{H11}, 12,13,15$ and 16) shale experiments.

\begin{tabular}{|l|c|c|}
\hline RUN & $\begin{array}{c}\text { Model Carbonate } \\
\text { Decomposition } \\
\%\end{array}$ & $\begin{array}{c}\text { Model Carbonate } \\
\text { Decomposition } \\
\%\end{array}$ \\
\hline \hline H8 & 16 & 30 \\
\hline H9 & 14 & 26 \\
\hline H10 & 5 & 14 \\
\hline H14 & 7 & 22 \\
\hline \hline H11 & 8 & 21 \\
\hline H12 & 10 & 20 \\
\hline H13 & 7 & 22 \\
\hline H15 & 28 & 45 \\
\hline H16 & 23 & 46 \\
\hline
\end{tabular}

The variation in carbonate decomposition from run to run is tied to changes in processing conditions, primarily temperature levels in the FBC. This is demonstrated in Fig. 2 where effective first order rate constants computed from data and model runs are plotted as a function of the reciprocal of the measured FBC temperature. The effective rate constants were computed assuming a decomposition rate proportional to the amount of carbonate (mineral carbon) remaining and assuming a nominal 45 second residence time at the FBC temperature. For the most part, the dependence shows a typical Arrhenius type behavior with temperature. The effective rate constant in the model calculations is below those obtained directly from 4TU-Pilot experimental data. The proportional discrepancy appears to be somewhat worse at lower temperatures. 


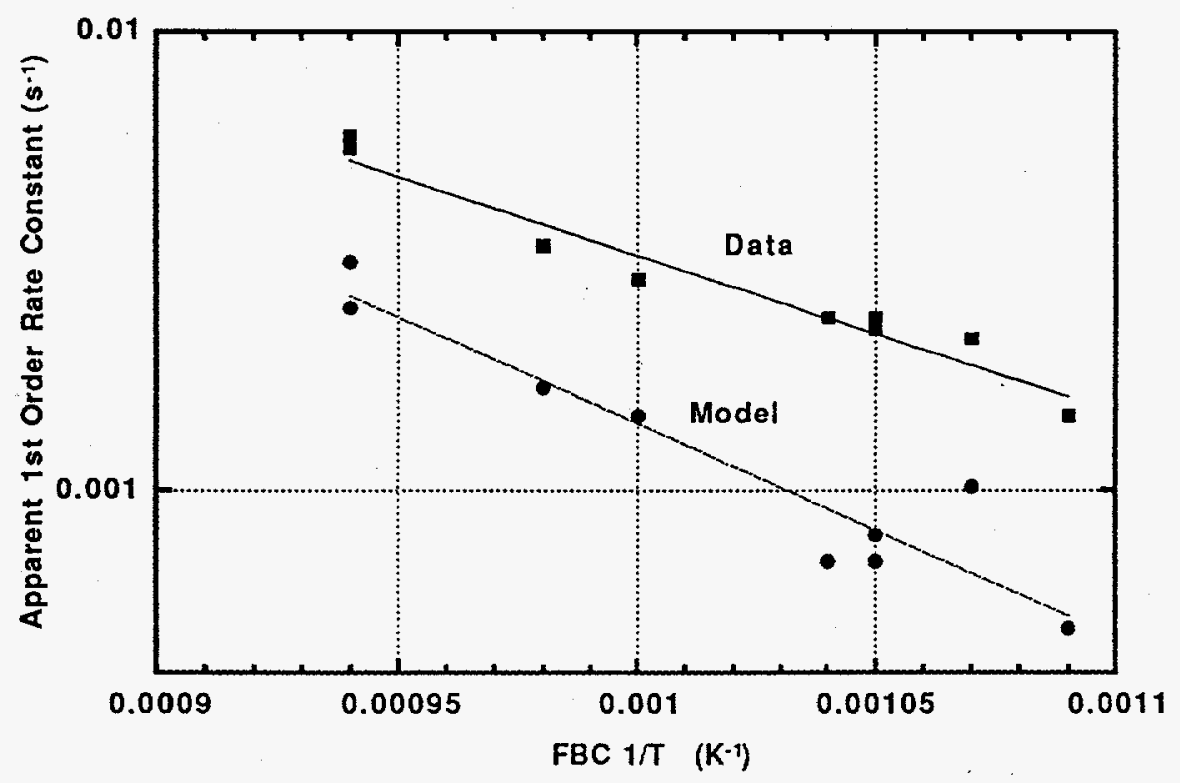

Figure 2. Apparent first order rate constant for carbonate decomposition calculated from data and OSP model calculations. Measured FBC temperatures and a residence time of 45 seconds have been assumed.

The model used in generating the results given above is a complete simulation of the 4TU-Pilot operation in that it includes pyrolysis, combustion and carbonate decomposition reactions. In addition, assumptions were made about the manner in which the shale particles broke and attrited in the process. This is a fairly complex model and requires considerable computation time. As a consequence parametric studies were not performed on uncertainties which could influence the estimation of the degree of carbonate decomposition.

Of particular interest, with respect to estimating the carbonate decomposition, is the nature of fines generation. This is important because in most cases one-half to three quarters of the solid material leaving the process is in the form of fines (defined here as any material less than 70 mesh, $0.21 \mathrm{~mm}$ ), and the fines leave the process in a manner different than the larger material. The large material exits the system by means of an overflow port in the FBC, while the fines are primarily carried out by gas entrainment. As a consequence the average exposure of the carbonate to the retort environment is closely coupled to the fines generation. For example, if the bulk of the fines are generated as the raw shale passes through the FBM, PYR and LFT then much of the carbonate may exit the system before passing through the FBC which is the unit which contributes the most solids residence time on the high temperature, combustion side, of the process. On the other hand, if the fines come primarily from recycle material then nearly all the material would have passed at least once through the FBC and one would compute a different amount of decomposition than in the former case even using the same kinetic relations. 
To quantitatively explore the influence of fines generation on the computed carbonate decomposition simplified OSP models have been developed which allow estimates of carbonate decomposition to be made. The simplified models require less than a minute of computation time and thus lend themselves to looking at a variety of assumptions regarding fines generation. Below, the carbonate decomposition data from the 4TUPilot is first presented along with some simple material balance results. This is followed by a description of and results from the simplified OSP models.

\section{TU-Pilot Carbonate Decomposition Data}

Experimental runs in the 4TU-Pilot, for the most part, consisted of processing one hopper of raw shale. At the nominal raw feed rate of $2-2.5 \mathrm{~kg} / \mathrm{min}$ the runs each lasted about four hours. The raw shale is prepared for a run in Master Batches. A Master Batch consists of about $2000 \mathrm{~kg}$, enough for three standard four hour runs. Two basic shale grades have been processed in the 4TU-Pilot, a lean grade of about $22 \mathrm{gal} / \mathrm{ton}$ Fischer Assay and a rich shale averaging about $38 \mathrm{gal} / \mathrm{ton}$. Pertinent data for the shale master batches are given in Tables 2 and 3 . Fines are defined here as -70 mesh particles, i.e., particles which pass through a standard screen with an opening of $0.21 \mathrm{~mm}$. The average particle size given in the tables are mass averaged values excluding the fines cut.

Carbonates in oil shale consist of a mixture of calcite $\left(\mathrm{CaCO}_{3}\right)$ and a mixed carbonate containing calcium, magnesium and iron. This mixed carbonate mineral is a complex mixture of various ratios of the cation components. Mixtures containing primarily magnesium and calcium are generally referred to as dolomite while those containing larger proportions or iron are known as ankerite. In the tables the amount of calcite and ankerite in each Master Batch was obtained from a formula which partitions the mineral carbon between calcite and non-calcite (referred to here as ankerite) forms based on cation ratios. This split is important since decomposition reaction rates are dependent on the carbonate form.

Carbonate decomposition between 14 and $49 \%$ of the available carbonate have been measured in a series of 16 runs using the 4TU-Pilot. These results are shown in Tables 4 and 5 along with some pertinent operating parameters. Since the FBC unit affords the most residence time at the highest temperatures, the manner in which it operates is important to the degree of carbonate decomposition. The tables indicate whether the unit was operated on air or a mixture of air and nitrogen. The recycle ratio referred to in the tables is the ratio of recycle material passing from the FBC into the FBM relative to the amount of raw shale feed. The amount of fines generated in the process is also an important consideration and the degree of fines generation is defined in the table by the relative amount of -70 mesh particles present in the solids exiting the process. 
Table 2. Lean Master Batch shale compositional data.

\begin{tabular}{|c|c|c|}
\hline Naster Batch \# & 2 & 7 \\
\hline \multicolumn{3}{|l|}{ Elemental Analysis } \\
\hline Total Carbon (\%) & 15.14 & 14.73 \\
\hline Hydrogen (\%) & 1.54 & 1.52 \\
\hline Nitrogen (\%) & 0.63 & 0.67 \\
\hline Sulfur $(\%)$ & 0.53 & 0.52 \\
\hline Acid CO2 $(\%)$ & 17.29 & 16.67 \\
\hline Mineral Carbon (\%) & 4.72 & 4.55 \\
\hline Organic Carbon (\%) & 10.42 & 10.18 \\
\hline \multicolumn{3}{|l|}{ Fischer Assay } \\
\hline Average Gallons-per-ton & 21.62 & 20.96 \\
\hline \multicolumn{3}{|l|}{ Particle Size } \\
\hline Average Particle Size (mm) & 1.3 & 1.6 \\
\hline Fines (\%) & 7 & 8 \\
\hline & & \\
\hline \multicolumn{3}{|l|}{ Selected Mineralogy } \\
\hline$C$ in Calcite (mol $\mathrm{C} / \mathrm{kg}$ raw) & & 0.71 \\
\hline $\mathrm{C}$ in Ankerite (mol C/kg raw) & & 3.234 \\
\hline Ankerite/Calcite (mole ratio) & 4.6 & 4.55 \\
\hline FeS2 (\%) & 0.6 & 0.78 \\
\hline & & \\
\hline \multicolumn{3}{|l|}{ Derived Raw } \\
\hline Rerogen (\%) & 12.34 & 12.06 \\
\hline \multicolumn{3}{|l|}{ Mineral Carbon $(\%)$} \\
\hline Associated with $\mathrm{Ca}$ & 2.78 & 2.68 \\
\hline Not associated with Ca & 1.94 & 1.86 \\
\hline Total & 4.72 & 4.55 \\
\hline FeS2 (\%) & 0.6 & 0.78 \\
\hline \multicolumn{3}{|l|}{ Typical Char } \\
\hline Char (\%) & 2.74 & 2.218 \\
\hline \multicolumn{3}{|l|}{ Mineral Carbon (\%) } \\
\hline Associated with $\mathrm{Ca}$ & 3.08 & 2.98 \\
\hline Not associated with $\mathrm{Ca}$ & 2.14 & 2.07 \\
\hline Total & 5.22 & 5.04 \\
\hline FeS2 $(\%)$ & 0.64 & 0.84 \\
\hline
\end{tabular}


Table 3. Rich Master Batch shale compositional data

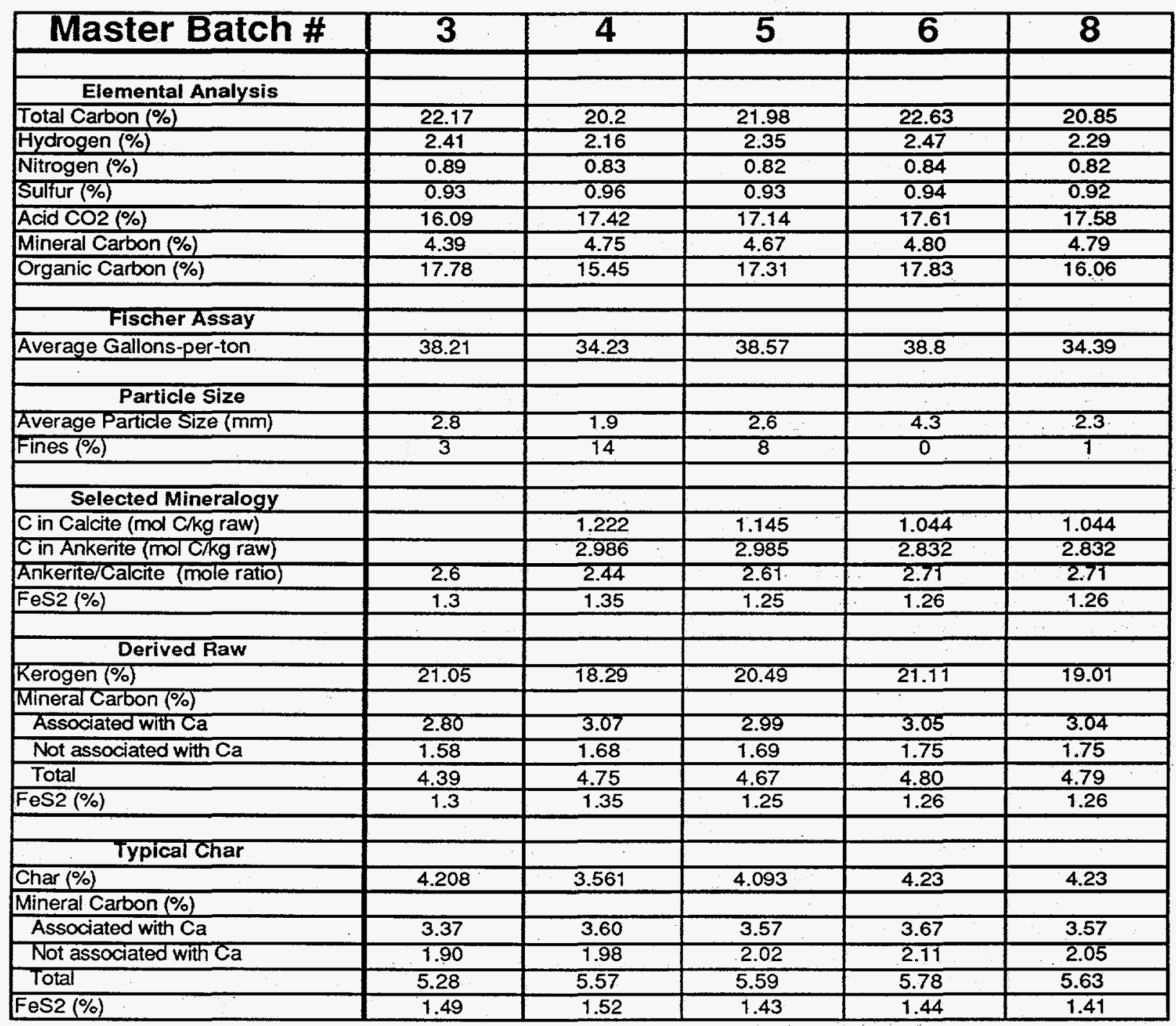


Table 4. Process data from five 4 TU-Pilot runs using lean shale

\begin{tabular}{|l||c|c|c|c|c|}
\hline Run & H10 & H14 & H19 & H20 & H21 \\
\hline \hline Master Batch \# & 2 & & & & \\
\hline & & & 7 & 7 & 7 \\
\hline Carbonate Decomposition (\%) & 14 & 22 & 34 & 42 & 39 \\
\hline & & & & & \\
\hline Pressure (kPa) & 147 & 144 & 155 & 157 & 167 \\
\hline & & & & & \\
\hline FBC & & & & & \\
\hline Gas inj. rate (mol/s) & 0.35 & 0.34 & 0.43 & 0.44 & 0.44 \\
\hline Air (\%) & 0 & 100 & 36 & 35 & 100 \\
\hline & & & & & \\
\hline Shale Feed Rate (kg/min) & 2.4 & 1.8 & 2.5 & 2.5 & 2.6 \\
\hline Shale Feed Total (kg) & 640 & 660 & 510 & 660 & 600 \\
\hline & & & & & \\
\hline Recycle Ratio & 3.3 & 3.8 & 2.3 & 2.2 & 1.9 \\
\hline & & & & & \\
\hline Spent fines (\%) & 29 & 33 & 29 & 27 & 25 \\
\hline & & & & & \\
\hline Temperatures (C) & & & & & \\
\hline PYR & 503 & 503 & 497 & 495 & 495 \\
\hline DFC & 659 & 642 & 699 & 729 & 708 \\
\hline FBC & 644 & 684 & 712 & 734 & 759 \\
\hline
\end{tabular}

Table 5. Process data from eleven 4TU-Pilot runs using rich shale

\begin{tabular}{|l||c|c|c|c|c|}
\hline \multicolumn{1}{|c|}{ Run } & H11 & H12 & H13 & H15 & H16 \\
\hline \hline & & & & & \\
\hline Master Batch \# & 4 & 4 & 5 & 5 & 5 \\
\hline & & & & & \\
\hline Carbonate Decomposition (\%) & 21 & 20 & 22 & 45 & 46 \\
\hline & & & & & \\
\hline Pressure (kPa) & 160 & 152 & 155 & 158 & 157 \\
\hline & & & & & \\
\hline FBC & 0.35 & 0.35 & 0.35 & 0.36 & 0.34 \\
\hline Gas inj. rate (mol/s) & 0 & 0 & 0 & 100 & 100 \\
\hline Air (\%) & & & & & \\
\hline & 2.4 & 2.4 & 2.1 & 2.1 & 2.1 \\
\hline Shale Feed Rate (kg/min) & 550 & 340 & 510 & 520 & 560 \\
\hline Shale Feed Total (kg) & & & & & \\
\hline & 2.8 & 2.9 & 3.1 & 3.2 & 2.1 \\
\hline Recycle Ratio & & & & & \\
\hline & 51 & 58 & 55 & 74 & 70 \\
\hline Spent fines (\%) & & & & & \\
\hline & & & & & \\
\hline Temperatures (C) & 504 & 500 & 507 & 548 & 497 \\
\hline PYR & 696 & 680 & 706 & 761 & 756 \\
\hline DFC & 678 & 665 & 681 & 787 & 792 \\
\hline FBC & & & & \\
\hline
\end{tabular}


Table 5. (cont'd) Process data from eleven 4TU-Pilot runs using rich shale

\begin{tabular}{|l||c|c|c|c|c|c|}
\hline Run & H22 & H23 & H24 & H25 & H26 & H27 \\
\hline \hline & & & & & & \\
\hline Master Batch \# & 6 & 6 & 3 & 3 & 3 & 8 \\
\hline & & & & & & \\
\hline Carbonate Decomposition (\%) & 49 & 41 & 31 & 29 & 34 & 32 \\
\hline & & & & & & \\
\hline Pressure (kPa) & 166 & 154 & 175 & 170 & 177 & 184 \\
\hline & & & & & & \\
\hline FBC & & & & & & \\
\hline Gas inj. rate (mol/s) & 0.44 & 0.53 & 0.21 & 0.40 & 0.40 & 0.37 \\
\hline Air (\%) & 100 & 66 & 100 & 0 & 0 & 0 \\
\hline Shale Feed Rate (kg/min) & 2.2 & 1.6 & 2.2 & 2.1 & 2.1 & 2.2 \\
\hline Shale Feed Total (kg) & 430 & 490 & 330 & 450 & 600 & 1090 \\
\hline & & & & & & \\
\hline Recycle Ratio & 2.7 & 2.7 & & 2.7 & & \\
\hline & & & & & & \\
\hline Spent fines (\%) & 78 & 71 & 32 & 79 & 61 & 65 \\
\hline & & & & & & \\
\hline Temperatures (C) & & & & & & \\
\hline PYR & 515 & 511 & 515 & 502 & 494 & 490 \\
\hline DFC & 735 & 726 & 680 & 744 & 758 & 737 \\
\hline FBC & 780 & 741 & 750 & 722 & 730 & 694 \\
\hline
\end{tabular}

Table 6. Additional process data and selected material balance results for five $4 \mathrm{TU}-$ Pilot runs using lean shale.

\begin{tabular}{|l||c|c|c|c|c|}
\hline \multicolumn{1}{|c|}{ Run } & H10 & H14 & H19 & H20 & H21 \\
\hline \hline & & & & & \\
\hline CO2 in Gas (vol. \%) & & & & & \\
\hline Pyrolysis Side Exit & 0.9 & 0.4 & 6.3 & 2.5 & 0.2 \\
\hline Combustion Side Exit & 9.4 & 10.4 & 13.2 & 14.4 & 14.5 \\
\hline FBC (by balance) & 12.5 & 10.4 & 12.3 & 13.5 & 13.5 \\
\hline DFC (by balance) & 4.7 & 14.3 & 14 & 17.4 & 17.4 \\
\hline & & & & & \\
\hline Mineral C (\%) & & & & & \\
\hline In Spent & 4.8 & 4.5 & 3.8 & 3.3 & 3.6 \\
\hline In PYR & 5.3 & 4.1 & 3 & 3.6 & 3.1 \\
\hline Estimate in Recycle & 5.3 & 3.8 & 2.6 & 3.0 & 2.1 \\
\hline Ratio SpentRecycle & 0.9 & 1.2 & 1.5 & 1.1 & 1.7 \\
\hline
\end{tabular}


Table 7. Additional process data and selected material balance results for eleven 4TU-Pilot runs using rich shale.

\begin{tabular}{|l||c|c|c|c|c|}
\hline \multicolumn{1}{|c|}{ Run } & $\mathrm{H11}$ & $\mathrm{H12}$ & $\mathrm{H13}$ & $\mathrm{H15}$ & $\mathrm{H16}$ \\
\hline \hline & & & & & \\
\hline CO2 in Gas (vol. \%) & & & & & \\
\hline Pyrolysis Side Exit & 3.2 & 4.5 & 1.8 & 9.3 & 5.2 \\
\hline Combustion Side Exit & 11.6 & 11 & 11.6 & 14.9 & 15.4 \\
\hline FBC (by balance) & 15.2 & 14.9 & 13.9 & 13.2 & 14.1 \\
\hline DFC (by balance) & 5.1 & 4.5 & 7 & 23.6 & 20.9 \\
\hline Mineral C (\%) & & & & & \\
\hline In Spent & & & & & \\
\hline In PYR & 4.9 & 5.0 & 4.6 & 3.5 & 3.4 \\
\hline Estimate in Recycle & & & 6 & 3.5 & 4.1 \\
\hline Ratio Spent/Recycle & & & 5.8 & 3.0 & 3.5 \\
\hline
\end{tabular}

\begin{tabular}{|l||c|c|c|c|c|}
\hline \multicolumn{1}{|c|}{ Run } & $\mathrm{H22}$ & $\mathrm{H23}$ & $\mathrm{H} 25$ & $\mathrm{H26}$ & $\mathrm{H27}$ \\
\hline \hline & & & & & \\
\hline CO2 in Gas (vol. \%) & & & & & \\
\hline Pyrolysis Side Exit & 0.6 & 3.8 & 3 & 2.5 & 2.8 \\
\hline Combustion Side Exit & 14.3 & 11.2 & 12.9 & 11.2 & $?$ \\
\hline FBC (by balance) & 18.7 & 7.4 & 7.7 & 7.2 & $?$ \\
\hline DFC (by balance) & 14.7 & 8.4 & 10.7 & 10.5 & 9.1 \\
\hline & & & & & \\
\hline Mineral C (\%) & & & & & \\
\hline In Spent & 3.8 & 4.0 & 4.1 & 4.2 & 4.4 \\
\hline In PYR & 3.6 & 3.7 & 4.3 & 4.5 & \\
\hline Estimate in Recycle & 2.9 & 3.1 & 4.0 & 4.2 & \\
\hline Ratio SpentRecycle & 1.3 & 1.3 & 1.0 & 1.0 & \\
\hline
\end{tabular}

In Tables 6 and 7 additional information pertinent to the issue of carbonate decomposition for these runs are presented. This includes measurements and estimates of carbon dioxide levels and mineral carbon levels. Measurements of gas composition in the two product streams, that exiting the combustion side and that exiting the pyrolysis side, were routinely made and averages for each run are presented in the table. Carbon dioxide levels present in several of the process units are of interest for modeling reasons, as will be described in a later section. During retort runs spot checks were made of gas composition in various units including those listed in the tables, however, a more consistent estimate is available from overall material balance computations performed for each run ${ }^{3}$ and it is these values reported for the FBC and $\mathrm{DFC}$ in the tables.

The mineral carbon (used here to mean carbonate carbon) levels for the spent material and material in the PYR at the end of most of the retort runs were measured. If it is 
assumed that the PYR sample at the end of the test is representative of the full test, and that no significant carbonate decomposition occurs in the FBM or PYR the measured mineral carbon values in the PYR along with those of the raw feed can be used to estimate the mineral carbon levels in the recycle material. These estimates are given in Tables 6 and 7. In several cases upsets at the time of shutdown made the samples in the PYR unrepresentative and thus they were not analyzed. Also shown is the ratio of the estimated mineral carbon in the recycle to the mineral carbon measured in the spent material. The average ratio is 1.16 indicating that the recycle material was only slightly richer in mineral carbon than the material exiting the process.

\section{OSP Mode1}

The Oil Shale Process (OSP) model is a general purpose model for modeling oil shale related processes. It allows various unit operations (process modules) to be connected in a manner which will simulate a desired process. Process modules are connected together with solid, gas and liquid streams. The model used to look at all aspects of the 4TU-Pilot operation consisted of approximately 70 process modules, 200 solid streams, 50 gas streams and 5 liquid streams. As mentioned above this relatively complex system took as much as 4 hours to run on an HP-9000/735 work station. To explore various assumptions and sensitivities related to carbonate decomposition two simpler configurations of the OSP model were constructed. The two differ in the assumptions made about the way fines exit the system.

A basic ingredient in both models is the kinetic expression used to compute the amount of carbonate decomposition. OSP has a kinetic expression based for computing carbonate decomposition on an analysis of the rather extensive data of Jukkola 4 . An engineering kinetic expression was developed several years ago from the Jukkola data and is reported by Lewis 5 .

Three carbonate mineral reactions are considered. One which looks at the non-calcite carbonates as represented here by magnesium carbonate

$$
\mathrm{MgCO}_{3} \Rightarrow \mathrm{MgO}+\mathrm{CO}_{2} \text {, }
$$

and two calcite reactions which are lumped together to form one calcite decomposition rate

$$
\begin{aligned}
& \mathrm{CaCO}_{3} \text { (Calcite) } \Rightarrow \mathrm{CaO}+\mathrm{CO}_{2} \\
& \mathrm{CaCO}_{3} \text { (Calcite) }+\mathrm{SiO}_{2} \Rightarrow \mathrm{CaSiO}_{3}+\mathrm{CO}_{2} .
\end{aligned}
$$

The decomposition rate for the carbonate not associated with calcium is assumed given by

$$
\begin{aligned}
& \text { rate }=k_{M_{g}} \rho_{M g} \\
& k_{M g}=A_{M g-1} \exp \left(\frac{-T_{M g-1}}{T}\right)\left(1-\beta_{C O_{2}}\right)+A_{M g-2} \exp \left(\frac{-T_{M g-2}}{T}\right) \beta_{C O_{2}} \\
& \beta_{C O_{2}}=\frac{y_{C O 2} P}{1.013 \times 10^{5}}
\end{aligned}
$$


where $k_{M g}$ is constrained to be greater than or equal to zero. (i.e. the reverse reaction is not allowed) and has units of reciprocal seconds. In the expression the $A$ 's are the Arrhenius' pre-exponential factors, the subscripted $T s$ are the activation temperatures, the unsubscripted $T$ is the system temperature, $y \mathrm{CO} 2$ is the mole fraction of carbon dioxide, $P$ is the pressure in Pascals, and $\rho_{M g}$ is the carbonate density. The dependence of carbon dioxide partial pressure, represented by the $\beta_{C O 2}$ factor, is based on experiments carried out with essentially no carbon dioxide present and with one atmosphere of carbon dioxide. The functional form simply allows reasonable interpolation between these two conditions. The subscript " $M g$ " is used to refer to all carbonates which cannot be associated with calcium. In the modeling two carbonate species are followed $\mathrm{CaCO}_{3}$ and $\mathrm{MgCO}_{3}$ representing calcium associated carbonate and non-calcium associated carbonate respectively.

The calcite decomposition consists of a self decomposition reaction which is highly inhibited by the presence of carbon dioxide and the calcite/quartz reaction having a form similar to that of the $\mathrm{MgCO}_{3}$ decomposition.

$$
\begin{aligned}
& \text { rate }=\left(k_{\text {Cal, Quart }}+k_{\text {Cal,Self }}\right) \rho_{\text {Cal }} \\
& k_{C a l, \text { Quartz }}=A_{C a l, \text { Quartz-1 }} \exp \left(\frac{-T_{C a l, \text { Quartz-1 }}}{T}\right)\left(1-\beta_{C O_{2}}\right)+A_{C a l, \text { Quartz-2 }} \exp \left(\frac{-T_{C a l, \text { Quarz-2 }}}{T}\right) \beta_{C O_{2}} \\
& k_{C a l, S e l f}=A_{C a l, S e l f} \exp \left(\frac{-T_{C a l, S e l f}}{T}\right)\left[1-\frac{y_{C O 2} P}{A_{C O 2-E Q} \exp \left(\frac{-T_{C O 2-E Q}}{T}\right)}\right]
\end{aligned}
$$

As in the $\mathrm{MgCO}_{3}$ decomposition the rate constants are limited to values greater than or equal to zero.

The values of the rate parameters are given in Table 8.

Table 8. Values of kinetic parameters for the kinetic model based on the Jukkola data

\begin{tabular}{|c||c|c|}
\hline Parameter & Value & Units \\
\hline \hline$A_{M g-1}$ & $4.08 \times 10^{7}$ & $1 / \mathrm{s}$ \\
\hline$T_{M g-1}$ & 23320 & $\mathrm{~K}$ \\
\hline$A_{M g-2}$ & $9.02 \times 10^{4}$ & $1 / \mathrm{s}$ \\
\hline$T_{M g-2}$ & 17010 & $\mathrm{~K}$ \\
\hline$A_{\text {Cal,Quartz-1 }}$ & $1.30 \times 10^{10}$ & $1 / \mathrm{s}$ \\
\hline$T_{a C l, \text { Quartz-1 }}$ & 27680 & $\mathrm{~K}$ \\
\hline$A_{\text {Cal, Quartz-2 }}$ & $5.60 \times 10^{8}$ & $1 / \mathrm{s}$ \\
\hline$T_{\text {Cal,Quartz-2 }}$ & 29620 & $\mathrm{~K}$ \\
\hline$A_{\text {Cal,Self }}$ & $8.52 \times 10^{12}$ & $1 / \mathrm{s}$ \\
\hline$T_{\text {Cal, Self }}$ & 40460 & $\mathrm{~K}$ \\
\hline$A_{\text {CO2-EQ }}$ & $1.94 \times 10^{13}$ & $1 / \mathrm{s}$ \\
\hline$T_{\text {CO2-EQ }}$ & 22360 & $\mathrm{~K}$ \\
\hline
\end{tabular}


Another possible source of carbonate loss is in the overall combustion reaction of iron sulfide. The net reaction is

$$
\mathrm{FeS}_{2}+2 \mathrm{CaCO}_{3}+3.75 \mathrm{O}_{2} \rightarrow 0.5 \mathrm{Fe}_{2} \mathrm{O}_{3}+2 \mathrm{CaSO}_{4}+2 \mathrm{CO}_{2} .
$$

The speed of this reaction and its extent depend primarily on the iron sulfide content of the shale since carbonate is present in large excess. The reaction proceeds rapidly in the presence of oxygen and therefore it is not unreasonable to assume that carbonate is consumed in the retort via this reaction. Based on iron sulfide levels in the shale this reaction could at most account for only a 3-6\% carbonate loss. As a consequence the reaction is not considered in the current model.

\section{OSP Model I}

The primary focus of the model studies was to determine the range of results possible with respect to carbonate decomposition using the kinetics outlined above as a function of fines generation and removal from the process. A schematic representation of model is given in Fig. 3.

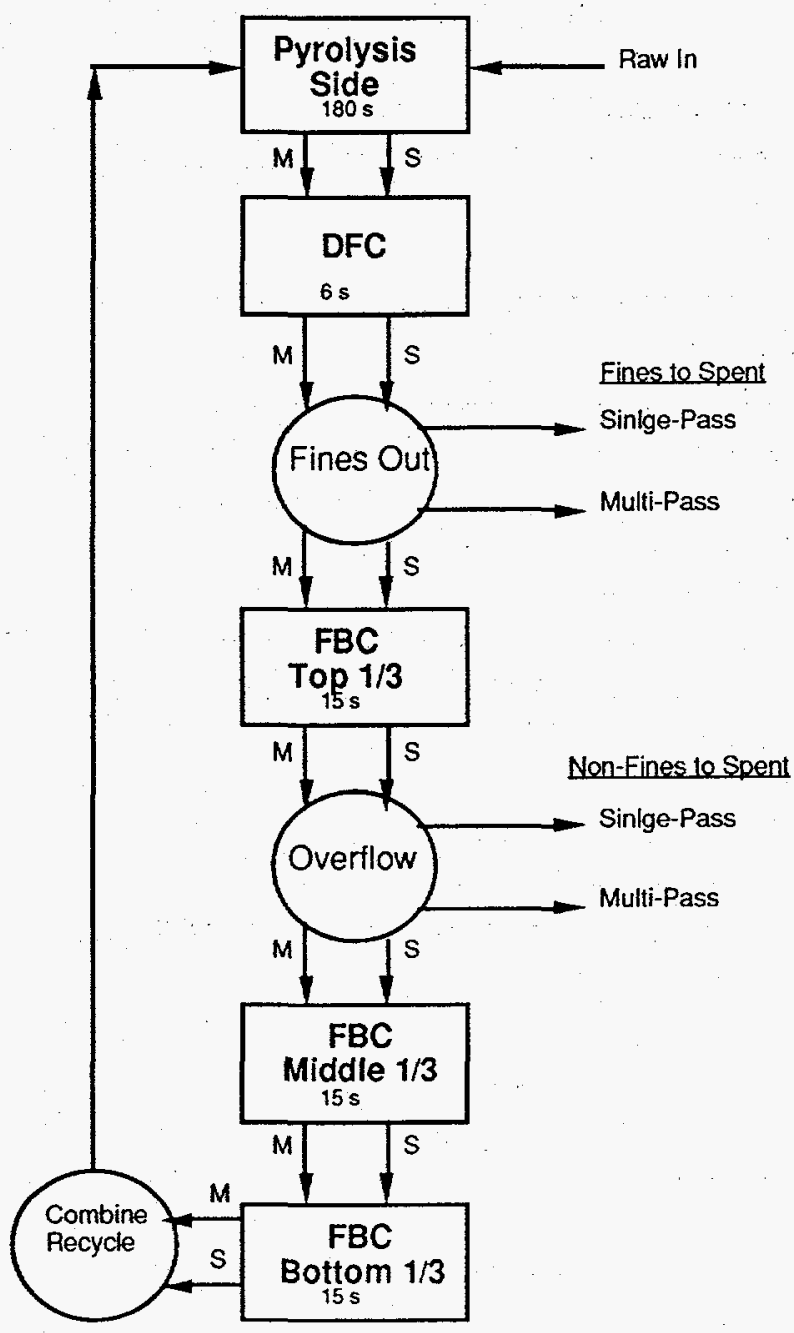

Figure 3. Schematic representation of OSP Model I showing solid streams. M and S denote multi- and single-pass solids respectively. 
This model consists of 14 OSP computational modules, 30 solid streams and 13 gas streams. Computation times of under one minute on the HP-9000/730 work station are typical. The overall processing steps occurring in the 4TU-Pilot have been greatly simplified. First only two basic solid stream types are considered, a single-pass stream, denoted by $S$ in the schematic, and a multi-pass or recycle stream denoted by $M$. In the real process a shale particle entering the system may stay in the process units for only a single pass or may be recycled for a number of passes. In the model this potential complex recycle process is simplified by lumping all solids which have been around the loop at least once into a single multi-pass stream having a single average composition arrived at as part of the computation procedure. The raw shale feed is used in the model is actually pyrolyzed shale, approximated by simply removing the kerogen fraction from the raw shale. In the five reaction modules the only reaction considered explicitly is the decomposition of carbonate.

A single computational module is used to compute the carbonate decomposition occurring on the low temperature pyrolysis side of the system. This module lumps together the PYR and FBM units. The block labeled DFC represents another computational module used to calculate decomposition occurring primarily in the DFC. The FBC, the unit with the greatest potential to cause carbonate decomposition, has been broken into three separate computational modules. This was done to better track the coarse of the decomposition and allow other phenomena related to solids residence time and gas atmospheres to be modeled.

No module representing the lift pipe has been explicitly included for several reasons. The primary reason is that the residence times in the lift pipe are quite short, 1-2 seconds. During the transit up the lift pipe combustion occurs and the temperature of the solid can change fairly rapidly. The degree of change is very dependent on such particle characteristics as size and organic carbon content. This level of detail goes beyond the scope of the simplified models considered here. Preliminary calculations suggested that even for those particle that have the potential to increase in temperature. most rapidly the very short residence time and carbon dioxide levels do not allow significant carbonate decomposition to occur. To partly compensate for the absence of the lift pipe the average residence time in the DFC unit has been increased slightly over what actually occurs in that unit.

In general gas compositions and temperatures are set in each unit based on experimental data and simple balances described earlier. These are used as needed in computing the decomposition rate of the carbonate.

The Pyrolysis Side unit uses a CO_CURRENT OSP reaction module. This module models changes in a plug flow reactor. Even though the flow of solid through the FBM and PYR is not strictly plug flow in nature it is felt that the plug flow assumption would adequately allow carbonate decomposition rates to be estimated. In the actual process the mixing and heating of cold raw input and hot recycled material occurs relatively rapidly a single temperature was used to characterize this module. The temperature chosen was that measured in the pyrolyzer bed. A total residence time of 180 seconds was assigned to this reactor which is typical of the average residence time in the PYR 
and FBM. In this simplified model no attempt was made to change this residence time in response to variations in feed and recycle rates. A single gas composition is assumed throughout the module and is set based on measured values for a particular run.

The DFC module again uses a CO_CURRENT OSP reaction module operating isothermally. The temperature is obtained from the exit temperature of the physical DFC unit. Temperatures measured in the DFC during a retort run do not tend to vary markedly in the unit. A fixed gas composition is used in the unit based on levels derived from simple material balance considerations. The nominal residence time for solids in the DFC is estimated to be 5 seconds. In this model the residence time has been increased to 6 seconds to compensate for the lack of an explicit unit corresponding to the lift pipe.

Unlike the other units the $\mathrm{FBC}$ is not modeled by a plug flow reactor, but instead it is modeled as three equal sized stirred tank reactors, CSTR OSP modules. This is done for several reasons. First, the unit is a bubbling bed and as a result solid mixing occurs. Also, even though solids enter the unit from the top they exit at three different points. Any fine material in the solid as it enters the unit has the potential to be entrained in the gas flow exiting the unit and never reach the bed. Material which does enter the bed may be elutriated and exit with the gas, may flow out of the unit into the spent hopper through the overflow port or may pass through the bed and exit at the bottom and become the recycle material. In general the actual history of solid in the bed may be quite complicated. In the model the behavior in the bed has been simplified in the following way. It is assumed that no fines are in the FBC bed and all solid material entering the bed passes through the first reactor module representing $1 / 3$ of the FBC bed. After passing through the first reactor module a split is made which represents the solid overflow. Equal fractions of single- and multi-pass material are removed and the fraction is set so that the remaining solid flow equals the desired recycle solid flow rate. The recycle solid stream then pass through the two other reactor modules representing the remainder of the FBC unit. A residence time of 15 seconds is used in each reactor module.

Each of the three FBC reactor beds used in the model are held at same temperature. This temperature is obtained from bed temperatures measured during a given run.

Since the direction of gas flow in the FBC is basically from bottom to top it is probable that the gas environment in the unit varies from bottom to top. The exact nature of the variation is fairly complicated because of the presence of bubble and emulsion phases, the contribution of combustion and evolution of carbon dioxide from carbonate decomposition. It is beyond the scope of the current investigation to deal with the variation of the gas composition in an exact fashion. Instead, simplified assumptions are made which hopefully capture the essence of the variation as it influences the carbonate decomposition reactions.

The carbonate decomposition is influenced by the carbon dioxide level of the gas phase. Low levels promote carbonate decomposition. To capture this feature the carbon dioxide levels in the bottom FBC reactor module are set strictly by the evolution of carbon dioxide from computed carbonate decomposition in this module and the mixing 
with injected feed gas. This assumption is fully justified for those cases in which pure nitrogen is used as the feed gas for the unit. For those experimental runs when oxygen is present in the feed the case is less clear because of the possibility of combustion reactions occurring. However, in most cases when air is used in the FBC the carbon levels of the spent shale is very low. This leads to a fuel lean environment in the FBC and under these conditions it is not unreasonable to assume that most of the combustion occurs in the upper part of the FBC leaving little fuel available in the bottom part of the unit and thus little carbon dioxide production from combustion. In the middle reactor module the gas environment is set in two different ways depending on whether air is present in the FBC feed gas. For those cases in which it is present the carbon dioxide level in the middle module is set using the estimated level exiting the FBC unit, this partially compensates for the complete lack of combustion assumed in the bottom module. For the pure nitrogen injection cases the gas exiting the bottom module is mixed with gas generated by carbonate decomposition in the middle module and the resulting carbon dioxide level is used in computing decomposition rates. Finally in either case the carbon dioxide level of the top module is set based on measured values.

The model assumes fines are generated after leaving the DFC unit. A different fraction, representing the attrition of large material to fines, is used for the single- and multi-pass material. Only combinations of fractions which lead to the correct total fines generation are used. It is assumed the fines immediately leave the system after generation.

The solid recycle is completed after the FBC by combining the single- and multi-pass material into a new multi-pass stream which, along with the fresh feed, enters the Pyrolysis Side unit.

A final simplification was made to allow parametric studies to be performed more readily. In reality the amount of carbonate decomposition computed for a given case would require the fines generation fractions used to be slightly altered to lead to an overall fines fraction in exact agreement with the data. This is a rather time consuming and tedious operation which could not be performed automatically by the model and thus would require repeated trial and error. Since the change in fractions is relatively small and should lead to little difference in computed carbonate decomposition, this was not done. The problem was handled in the following manner. An artificially low carbonate level in inert solid was used in the computations and as a result the amount of carbonate decomposition did not change the overall amount of fines generation implemented in the model through the use of fractional splits. Since the kinetics are all assumed to be first order in carbonate species results are meaningful for the true levels as long as appropriate ratios are used and appropriate ranges of fines fractions can be computed based on simple overall balances. For those cases where carbon dioxide levels are computed as part of the calculations gas flows were appropriately adjusted.

The primary parameter to be explored with the model was the influence of the relative amount of fines generation between single- and multi-pass solid material. This is potentially an important consideration because as the amount of fines from the singlepass material increases the fraction of material which never enters the FBC increases. 
Four retort runs were chosen to be modeled. These span a carbonate decomposition range of 14 to $45 \%$ as measured as a percentage of the original carbonate. In the model the relative amount of fines coming from the single-pass and multi-pass material are specified by fractions which split the corresponding stream between fines and nonfines. In each case a range of fines generation fractions were assumed spanning the limits of essentially all fines generated from multi-pass material and all fines generated from single-pass material. The computed carbonate decomposition for each of the runs are given in Tables 9-12. Results are included in each case for fines generation fractions which are equal for each stream type and also for a set of fractions which yield an equal amount of fines from each stream. In this later case the single-pass fines fraction is about three to four times larger because of the relative size of the multi-pass stream, essentially the solid recycle stream, and the single-pass stream which is essentially the feed stream.

Table 9. Model I results for $\mathrm{H} 15$ carbonate decomposition as a function of fines generation from single- and multi-pass material. Data show a $45 \%$ decomposition level. For the fraction pair $0.37,0.093$ the fines generated from single- and multi-pass solid is equal.

\begin{tabular}{|c|c||c|}
\hline $\begin{array}{c}\text { Single-Pass Fraction } \\
\text { to Fines }\end{array}$ & $\begin{array}{c}\text { Multi-Pass } \\
\text { Fraction to Fines }\end{array}$ & $\begin{array}{c}\text { Decomposition } \\
(\%)\end{array}$ \\
\hline \hline 0.010 & 0.183 & 32.0 \\
\hline 0.100 & 0.160 & 31.1 \\
\hline 0.148 & 0.148 & 30.6 \\
\hline 0.370 & 0.093 & 27.9 \\
\hline 0.500 & 0.060 & 25.7 \\
\hline 0.730 & 0.003 & 19.7 \\
\hline
\end{tabular}

Table 10. Model I results for $\mathrm{H} 25$ carbonate decomposition as a function of fines generation from single- and multi-pass material. Data show a $29 \%$ decomposition level. For the fraction pair $0.395,0.116$ the fines generated from single- and multi-pass solid is equal.

\begin{tabular}{|c|c||c|}
\hline $\begin{array}{c}\text { Single-Pass Fraction } \\
\text { to Fines }\end{array}$ & $\begin{array}{c}\text { Multi-Pass Fraction } \\
\text { to Fines }\end{array}$ & $\begin{array}{c}\text { Decomposition } \\
(\%)\end{array}$ \\
\hline \hline 0.010 & 0.229 & 11.6 \\
\hline 0.100 & 0.203 & 11.4 \\
\hline 0.180 & 0.180 & 11.2 \\
\hline 0.395 & 0.116 & 10.5 \\
\hline 0.600 & 0.056 & 9.5 \\
\hline 0.780 & 0.003 & 7.9 \\
\hline
\end{tabular}


Table 11. Model I results for $\mathrm{H} 13$ carbonate decomposition as a function of fines generation from single- and multi-pass material. Data show a 22\% decomposition level. For the fraction pair $0.275,0.071$ the fines generated from single- and multi-pass solid is equal.

\begin{tabular}{|c|c||c|}
\hline $\begin{array}{c}\text { Single-Pass Fraction } \\
\text { to Fines }\end{array}$ & $\begin{array}{c}\text { Multi-Pass Fraction } \\
\text { to Fines }\end{array}$ & $\begin{array}{c}\text { Decomposition } \\
(\%)\end{array}$ \\
\hline \hline 0.010 & 0.138 & 4.7 \\
\hline 0.112 & 0.112 & 4.7 \\
\hline 0.275 & 0.071 & 4.5 \\
\hline 0.400 & 0.038 & 4.4 \\
\hline 0.540 & 0.003 & 4.1 \\
\hline
\end{tabular}

Table 12. Model I results for $\mathrm{H} 10$ carbonate decomposition as a function of fines generation from single- and multi-pass material. Data show a $14 \%$ decomposition level. For the fraction pair $0.145,0.039$ the fines generated from single- and multi-pass solid is equal.

\begin{tabular}{|c|c||c|}
\hline $\begin{array}{c}\text { Single-Pass Fraction } \\
\text { to Fines }\end{array}$ & $\begin{array}{c}\text { Multi-Pass Fraction } \\
\text { to Fines }\end{array}$ & $\begin{array}{c}\text { Decomposition } \\
(\%)\end{array}$ \\
\hline \hline 0.010 & 0.076 & 1.9 \\
\hline 0.061 & 0.061 & 1.9 \\
\hline 0.145 & 0.039 & 1.9 \\
\hline 0.280 & 0.003 & 1.9 \\
\hline
\end{tabular}

The variation of computed carbonate decomposition was a much weaker function of fines generation fractions than was anticipated. Only the extreme assumption of essentially all fines generated from the single-pass material lead to significant reductions in computed carbonate decomposition. On the other hand fines generation from only multi-pass material did not greatly increase the computed carbonate decomposition over the less extreme assumptions. In each case considered the model calculation of carbonate decomposition is substantially lower than that observed in the retort runs. Even for cases where essentially all the single-pass material passes through the FBC, low single-pass to fines fractions, the carbonate decomposition is $12-17 \%$ below the measured values, and on a proportional bases as much as a factor of seven too low for the lower carbonate decomposition runs.

For convenience important data for the four runs modeled are summarized in Table 13. For the two lower carbonate decomposition cases, $\mathrm{H} 13$ and H10, essentially all the computed carbonate composition was from the non-calcite carbonate. The reason for this is the lower FBC temperatures in these runs. The carbon dioxide inhibition of the calcite decomposition reaction in the kinetic formulation shuts of calcite decomposition at temperatures below $700 \mathrm{C}$ if the carbon dioxide levels are $1 \%$ or higher. In contrast, for H15 over one-third of the computed carbonate decomposition is from calcite. Because of the low temperatures very little carbonate decomposition is computed on the pyrolysis side, less then $0.2 \%$. Most of the decomposition is computed to occur in the 
FBC. Its contribution ranges from one-third of the total in $\mathrm{H} 10$ to over three-quarters of the total in $\mathrm{H} 15$. For runs $\mathrm{H} 10, \mathrm{H} 13$ and $\mathrm{H} 25$ the computed decomposition in the FBC is fairly uniformly distributed between the three reactor modules used in the simulation. In H15 however, well over one-half of the computed decomposition in the unit occurs in the bottom module. The primary reason for this is the lower computed carbon dioxide level in the bottom of the unit of about $7 \%$ (mole \%) compared to an average exit carbon dioxide level of $24 \%$.

Table 13. Summary retort data for the four retort runs used in the modeling studies

\begin{tabular}{|c||c|c|c|c|c|}
\hline & $\begin{array}{c}\text { Carbonate } \\
\text { Decomposition }\end{array}$ & \multicolumn{2}{|c|}{ Temperatures (C) } & Air in & Spent Fines \\
\hline Run & \%) & PYR & FBC & FBC & $(\%)$ \\
\hline \hline H15 & 44 & 548 & 787 & Yes & 74 \\
\hline H25 & 29 & 502 & 722 & No & 79 \\
\hline H13 & 22 & 507 & 681 & No & 55 \\
\hline H10 & 14 & 503 & 644 & No & 29 \\
\hline
\end{tabular}

Results of the model calculations indicate that using the kinetic expression describe above and a variety of assumptions about the split between fines generation by singleand multi-pass material computed carbonate decomposition levels are well below those measured. To further explore the impact of fines generation on carbonate decomposition a modified model was constructed with the intent of modeling a system in which the maximum credible exposure of input solid material to the high temperature FBC is assumed. This variation of the OSP model is described in the next section.

\section{OSP Model II}

Model II varies from Model I in the assumption made about the generation of fines. In Model I it was assumed that fines were generated prior to the solids reaching the FBC and were removed with the exiting gas before entering the FBC bed. This meant that they never encountered the extended residence time at the hottest system temperatures which lead to carbonate decomposition. In Model II an extreme assumption about fines generation is made which maximizes the contact of all solids with the FBC bed environment. It is assumed that all solids enter the FBC bed and that fines are generated in the bed. Further, it is assumed that the generated fines stay in the bed as long as the larger solids which are passing out the bottom of the bed to form the recycle stream.

The model is shown schematically in Fig. 4. As in Model I the overflow material is taken out of the system after passing through the top third of the FBC bed. The fines are not removed until the solids exit at the bottom of the FBC. All other assumptions about temperatures and gas composition are the same as for Model I. 


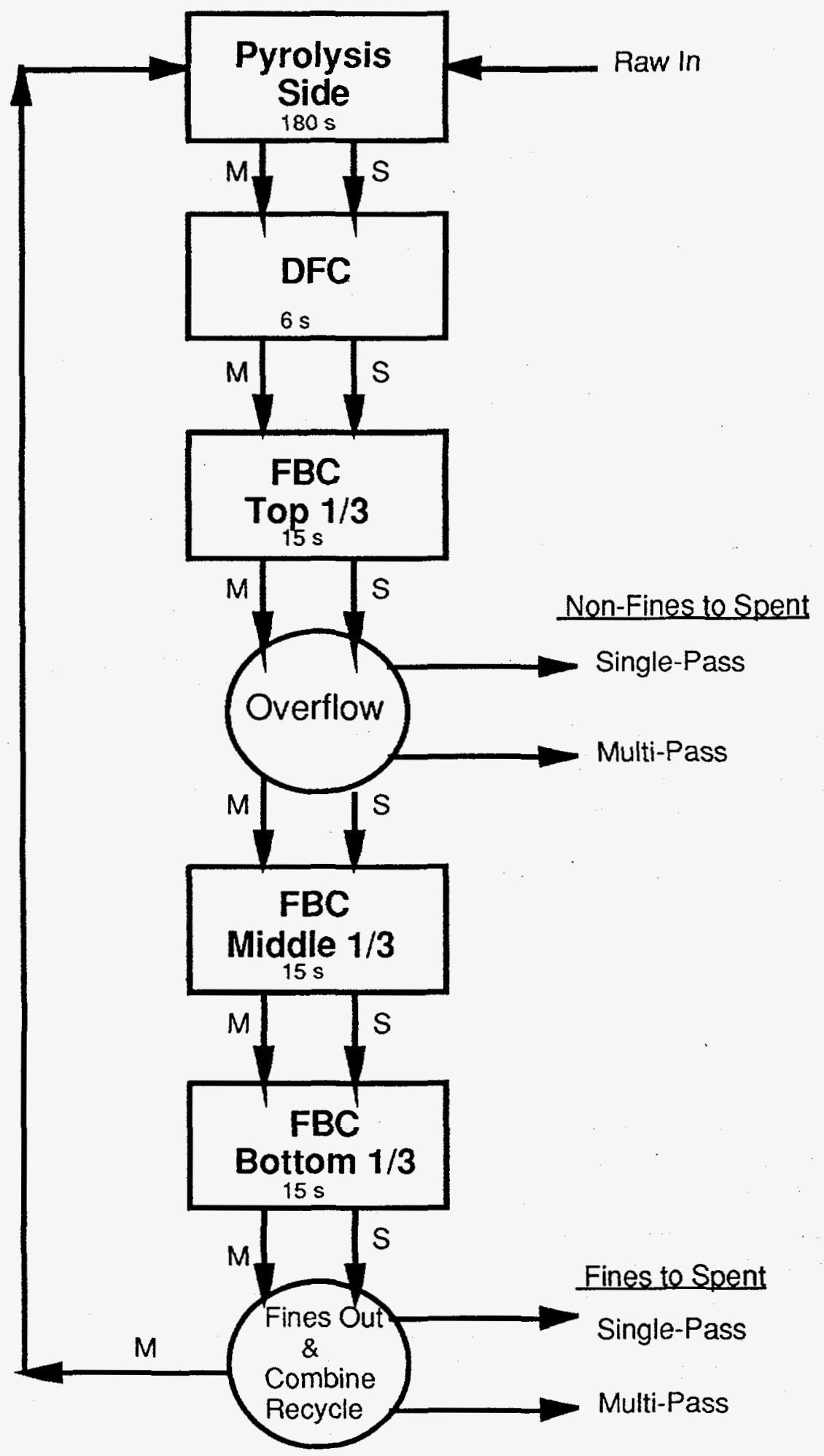

Figure 4. Schematic representation of OSP Model II showing solid streams. M and S denote multi- and single-pass solids respectively.

As with Model I the amount of single- and multi-pass material which attrits to fines is a parameter of the model. However, because of the nature of the fines generation the computed decomposition is an even weaker function of the relative split between these 
two sources. As in Model I it is assumed that the overflowed solids have a single-pass to multi-pass solid ratio equal to that in bed from which they come. In Table 14 results for Model II are given for a single fines split between single- and multi-pass material. This is the fractions which lead to equal fines generation from both material types. For convenience Model I results for the equal fines generation case also listed along with the measured carbonate decomposition.

Table 14. Model II results for carbonate decomposition as a function of fines generation from single- and multi-pass material. Data show a $14 \%$ decomposition level. For the fraction pair $0.145,0.039$ the fines generated from single- and multi-pass solid is equal. Model I results for the equal fines case is included for comparison.

\begin{tabular}{|c||c|c|c||c|c|}
\hline Run & $\begin{array}{c}\text { Model II } \\
\text { Single-Pass } \\
\text { Fraction to } \\
\text { Fines }\end{array}$ & $\begin{array}{c}\text { Model II } \\
\text { Multi-Pass } \\
\text { Fraction to } \\
\text { Fines }\end{array}$ & $\begin{array}{c}\text { Model II } \\
\text { Decomposition } \\
(\%)\end{array}$ & $\begin{array}{c}\text { Model I } \\
\text { Decomposition } \\
(\%)\end{array}$ & $\begin{array}{c}\text { Data } \\
\text { Decomposition } \\
(\%)\end{array}$ \\
\hline \hline $\mathrm{H} 15$ & 0.347 & 0.097 & 30 & 27.9 & 44 \\
\hline $\mathrm{H} 25$ & 0.376 & 0.121 & 11 & 10.5 & 29 \\
\hline $\mathrm{H} 13$ & 0.249 & 0.077 & 5.1 & 5 & 22 \\
\hline $\mathrm{H} 10$ & 0.124 & 0.045 & 2.1 & 2.1 & 14 \\
\hline
\end{tabular}

Model II calculations are not much different from those of Model I. The computed carbonate decomposition is well below the measured value even for this extreme assumption about the nature of fines generation and removal from the system. It is therefore concluded that the kinetic expressions defined above do not adequately describe the carbonate decomposition occurring in the retort.

Recently Watkins et $\mathrm{al}^{6}$ have done kinetic experiments looking at carbonate decomposition of shales used in the LLNL retort. The results indicate that in the carefully controlled bench scale experiments the rate of carbonate decomposition of the shale is under predicted by kinetic model derived from the Jukkola data. Although the Watkins experiments were not extensive enough to develop a full kinetic expression, several simple expressions were arrived at which fit the new data. One of these expressions has been used along with Model I to calculate carbonate decomposition for the four retort runs studied above. The simple kinetic expression used and the results are discussed in the next section.

\section{OSP Model I with Faster Kinetics}

In the simplified kinetic expression based on the work of Watkins only two reactions are considered. One is the decomposition of the non-calcium component of the carbonate, modeled here as decomposition of magnesium carbonate, and the other is the decomposition of calcite.

The rate of magnesium carbonate decomposition to carbon dioxide and magnesium oxide is assumed to be a simple first order expression given by 


$$
\text { rate }=A_{M_{g}} \exp \left(\frac{-T_{M_{g}}}{T}\right) \rho_{M_{g}}
$$

where the " $M g$ " subscript refers to magnesium carbonate.

The rate of calcite decomposition is also taken as a simple first order expression, but it has been assumed that the inhibition of the decomposition by carbon dioxide is given by the equilibrium relation defined previously. The rate expression is thus

rate $=A_{C a l} \exp \left(\frac{-T_{C a l}}{T}\right)\left[1-\frac{y_{C O 2} P}{A_{C O 2-E Q} \exp \left(\frac{-T_{C O 2-E Q}}{T}\right)}\right] \rho_{C a l}$

where the "Cal" subscript refers to calcium carbonate, or calcite.

The values of the kinetic parameters used are given in Table 15.

Table 15. Parameters for simplified fast kinetic model

\begin{tabular}{|c||c|c|}
\hline Parameter & Value & Units \\
\hline \hline$A_{M g}$ & $1.81 \times 10^{5}$ & $1 / \mathrm{s}$ \\
\hline$T_{M g}$ & 16000 & $\mathrm{~K}$ \\
\hline$A_{\mathrm{Cal}}$ & $3.96 \times 10^{12}$ & $1 / \mathrm{s}$ \\
\hline$T_{\mathrm{Cal}}$ & 32000 & $\mathrm{~K}$ \\
\hline$A_{\mathrm{CO} 2-\mathrm{EQ}}$ & $1.94 \times 10^{13}$ & $1 / \mathrm{s}$ \\
\hline$T_{\mathrm{CO} 2-\mathrm{EQ}}$ & 22360 & $\mathrm{~K}$ \\
\hline
\end{tabular}

Computed carbonate decomposition levels for a range of fines generation fractions are given in Tables 16-19. They agree much more closely with the measured values than those using the Jukkola derived kinetics. Except at the extreme of essentially all fines produced from the single-pass material, the variation of computed decomposition with source of fines is relatively mild. For runs $\mathrm{H} 15, \mathrm{H} 25$ and $\mathrm{H} 13$, all rich shale runs, the calculations underestimate the amount of carbonate decomposition by about $2-5 \%$. It is interesting to note that this is about the level of carbonate loss one could expect from the net combustion of iron sulfide. For the lean $\mathrm{H} 10$ run the computed carbonate decomposition, however, is high by about $3 \%$. 
Table 16. Model I results for $\mathrm{H} 15$ carbonate decomposition as a function of fines generation from single- and multi-pass material using Watkins kinetics. Data show a 45\% decomposition level. For the fraction pair $0.37,0.093$ the fines generated from single- and multi-pass solid is equal.

\begin{tabular}{|c|c||c|}
\hline $\begin{array}{c}\text { Single-Pass } \\
\text { Fraction to Fines }\end{array}$ & $\begin{array}{c}\text { Multi-Pass } \\
\text { Fraction to Fines }\end{array}$ & $\begin{array}{c}\text { Decomposition } \\
(\%)\end{array}$ \\
\hline \hline 0.010 & 0.183 & 42.4 \\
\hline 0.100 & 0.160 & 41.0 \\
\hline 0.148 & 0.148 & 40.2 \\
\hline 0.370 & 0.093 & 36.5 \\
\hline 0.500 & 0.060 & 33.7 \\
\hline 0.730 & 0.003 & 28.3 \\
\hline
\end{tabular}

Table 17. Model I results for $\mathrm{H} 25$ carbonate decomposition as a function of fines generation from single- and multi-pass material using Watkins kinetics. Data show a $29 \%$ decomposition level. For the fraction pair $0.395,0.116$ the fines generated from single- and multi-pass solid is equal.

\begin{tabular}{|c|c||c|}
\hline $\begin{array}{c}\text { Single-Pass } \\
\text { Fraction to Fines }\end{array}$ & $\begin{array}{c}\text { Multi-Pass } \\
\text { Fraction to Fines }\end{array}$ & $\begin{array}{c}\text { Decomposition } \\
(\%)\end{array}$ \\
\hline \hline 0.010 & 0.229 & 26.4 \\
\hline 0.100 & 0.203 & 24.9 \\
\hline 0.180 & 0.180 & 23.6 \\
\hline 0.395 & 0.116 & 19.9 \\
\hline 0.780 & 0.003 & 14.6 \\
\hline
\end{tabular}

Table 18. Model I results for $\mathrm{H} 13$ carbonate decomposition as a function of fines generation from single- and multi-pass material using Watkins kinetics. Data show a $22 \%$ decomposition level. For the fraction pair $0.275,0.071$ the fines generated from single- and multi-pass solid is equal.

\begin{tabular}{|c|c||c|}
\hline $\begin{array}{c}\text { Single-Pass } \\
\text { Fraction to Fines }\end{array}$ & $\begin{array}{c}\text { Multi-Pass } \\
\text { Fraction to Fines }\end{array}$ & $\begin{array}{c}\text { Decomposition } \\
(\%)\end{array}$ \\
\hline \hline 0.010 & 0.138 & 21.5 \\
\hline 0.112 & 0.112 & 20.3 \\
\hline 0.275 & 0.071 & 18.3 \\
\hline 0.540 & 0.003 & 14.3 \\
\hline
\end{tabular}


Table 19. Model I results for $\mathrm{H} 10$ carbonate decomposition as a function of fines generation from single- and multi-pass material using Watkins kinetics. Data show a $14 \%$ decomposition level. For the fraction pair $0.145,0.039$ the fines generated from single- and multi-pass solid is equal.

\begin{tabular}{|c|c||c|}
\hline $\begin{array}{c}\text { Single-Pass } \\
\text { Fraction to Fines }\end{array}$ & $\begin{array}{c}\text { Multi-Pass } \\
\text { Fraction to Fines }\end{array}$ & $\begin{array}{c}\text { Decomposition } \\
(\%)\end{array}$ \\
\hline \hline 0.010 & 0.076 & 17.2 \\
\hline 0.061 & 0.061 & 16.9 \\
\hline 0.145 & 0.039 & 16.3 \\
\hline 0.280 & 0.003 & 15.1 \\
\hline
\end{tabular}

Additional information is computed by the model in the course of calculating the overall carbonate decomposition. Selected results are presented in Tables 20-22. The results are presented for the case in which the fines generation fractions are equal. The tables show that the calculated carbonate decomposition is dominated by the magnesium carbonate decomposition. It should be remembered that in the model the magnesium carbonate represents all non-calcium components of the carbonate. Except for $\mathrm{H} 15$, in which the FBC was operating at nearly $800 \mathrm{C}$, the amount of calcite decomposition is computed to be essentially zero.

Table 20. Model I results using the fast kinetic expression showing the relative contribution of carbonate type and particle type to overall carbonate decomposition.

\begin{tabular}{|c|c|c|c|c|}
\hline & \multicolumn{2}{|c|}{ Carbonate Decomposition } & \multicolumn{2}{|c|}{ Carbonate Decomposition } \\
\hline Run & $\begin{array}{c}\% \text { From } \\
\text { CaCOB }\end{array}$ & $\begin{array}{l}\% \text { From } \\
\mathrm{MaCO} 3\end{array}$ & $\begin{array}{c}\% \text { From } \\
\text { Single-Pass }\end{array}$ & $\begin{array}{c}\% \text { From } \\
\text { Multi-Pass }\end{array}$ \\
\hline $\mathrm{H} 15$ & 12 & 29 & $\overline{22}$ & 18 \\
\hline $\mathrm{H} 25$ & 0 & 24 & 13 & 10 \\
\hline $\mathrm{H} 13$ & 0 & 20 & 8 & 12 \\
\hline $\mathrm{H} 10$ & 0 & 17 & 6 & 11 \\
\hline
\end{tabular}

Table 21. Model I results using the fast kinetic expression showing the contribution of each unit to the overall carbonate decomposition.

\begin{tabular}{|c||c|c|c|}
\hline \multicolumn{1}{|c||}{} & \multicolumn{3}{c|}{ Carbonate Decomposition } \\
\hline \hline Run & \% in PYR & $\%$ in DFC & \% in FBC \\
\hline H15 & 5 & 7 & 28 \\
\hline$H 25$ & 2 & 7 & 14 \\
\hline$H 13$ & 4 & 6 & 11 \\
\hline$H 10$ & 4 & 4 & 9 \\
\hline
\end{tabular}


Table 22. Model I results using the fast kinetic expression showing the ratio of mineral carbon remaining in the spent fines and nonfines.

\begin{tabular}{|c||c|}
\hline Run & $\begin{array}{c}\text { Spent Mineral C } \\
\text { Fines/Nonfines }\end{array}$ \\
\hline $\mathrm{H} 15$ & 0.98 \\
\hline $\mathrm{H} 25$ & 0.98 \\
\hline $\mathrm{H} 13$ & 0.99 \\
\hline $\mathrm{H} 10$ & 0.99 \\
\hline
\end{tabular}

The amount of computed decomposition arising from the single- and multi-pass material is approximately equal. The contribution from the single-pass material is slightly higher for the hotter higher decomposition cases, while the multi-pass material contributes more to the lower decomposition cases.

In each case more than half of the carbonate decomposition is computed to occur in the FBC. For the higher decomposition results more than two thirds of the decomposition is computed to be in the FBC.

Table 22 lists the computed relative amounts of mineral carbon (i.e. carbonates) remaining in the spent material based on size. The table indicates that in each case the amount of decomposition undergone by the fine material and that undergone by the larger material is almost exactly equal. This result is somewhat surprising since residence times for fines and large material in the model are not necessarily equal.

Some data is available concerning the relative mineral content of size classes of spent material for actual retort runs. Most of the data is from later runs where the primary collection of solid leaving the system entrained in the gas stream and that exiting via the FBC overflow were separated. Table 23 summarizes this data for the later runs. Table 24 gives data on an earlier run where analysis of several size classes where performed. In each case the amount of mineral carbon remaining in the fines and the larger material are roughly equal. This result is consistent with the model results.

Table 23. Distribution of mineral carbon in spent shale from three retort runs

\begin{tabular}{|c||c||c|c||c|}
\hline Run & $\begin{array}{c}\text { Spent } \\
\text { \% Fines }\end{array}$ & $\begin{array}{c}\text { Fines } \\
\text { Mineral C } \\
\text { (wt. \%) }\end{array}$ & $\begin{array}{c}\text { Nonfines } \\
\text { Mineral C } \\
\text { (wt. \%) }\end{array}$ & $\begin{array}{c}\text { Mineral C } \\
\text { Fines/Nonfines }\end{array}$ \\
\hline \hline $\mathrm{H} 25$ & 78 & 4.1 & 3.9 & 1.05 \\
\hline $\mathrm{H} 26$ & 57 & 3.8 & 4.2 & 0.9 \\
\hline $\mathrm{H} 27$ & 64 & 4.3 & 4.8 & 0.9 \\
\hline
\end{tabular}


Table 24. Distribution of mineral carbon as a function of size class in spent shale from retort run $\mathrm{H} 8$.

\begin{tabular}{|c||c|}
\hline Material & $\begin{array}{c}\text { Mineral C } \\
\text { (wt. \%) }\end{array}$ \\
\hline \hline Spent $5 \mathrm{~mm}$ & 3.8 \\
\hline Spent $2 \mathrm{~mm}$ & 4.2 \\
\hline Spent Fines & 3.8 \\
\hline Spent Ave. & 3.9 \\
\hline \hline Kerogen-Free Feed & 5.4 \\
\hline
\end{tabular}

Unlike results obtained with kinetics fit to the Jukkola data, results using the faster kinetics show a portion of the carbonate decomposition occurring on the pyrolysis side of the system as much as one-half the total decomposition for the low decomposition case H10. During operation of the retort, gas composition and flows from the pyrolysis side are monitored. This measured rate of carbon dioxide leaving with the pyrolysis gas is compared in Table 25 to amounts computed using the fast kinetic model. While not conclusive, the results indicate that calculated estimates of carbon dioxide production from carbonate decomposition on the pyrolysis side of the system are consistent with the data. The measured pyrolysis side carbon dioxide production, on a mole basis, is only a fraction of the total carbon production rate which is of the order of $500 \mathrm{mmol} / \mathrm{s}$. The bulk of the carbon production is from organic sources. In light of the large amounts of carbon present and the possibility of other carbon dioxide sources the level of agreement is surprising. The calculations suggest that much, if not all, of the carbon dioxide found in the pyrolysis gases is inorganic in origin and therefore the amount from organic sources is relatively small.

Table 25. Measured carbon dioxide production from the pyrolysis side of the system compared to computed amounts from carbonate decomposition

\begin{tabular}{|c||c|c|}
\hline Run & $\begin{array}{c}\text { Calculated CO2 } \\
\text { from PYR } \\
\text { (mmol/s) }\end{array}$ & $\begin{array}{c}\text { Measured CO2 } \\
\text { from PYR } \\
\text { (mmol/s) }\end{array}$ \\
\hline \hline $\mathrm{H} 15$ & 6.6 & 12.3 \\
\hline $\mathrm{H} 25$ & 2.7 & 2.3 \\
\hline $\mathrm{H} 13$ & 4.7 & 2.0 \\
\hline $\mathrm{H} 10$ & 6.7 & 8.1 \\
\hline
\end{tabular}

\section{Conclusions}

Model calculations indicate that the computed degree of carbonate decomposition is not strongly dependent on the manner in which fines are generated in and leave the system. Only in extreme cases where it is assumed that all the fines come from the single-pass material are significantly different, reduced, levels of carbonate decomposition predicted. 
In all model results using the kinetic model based on the Jukkola 4,5 data levels of carbonate decomposition well below those measured in the 4TU-Pilot experiments are . computed. On a absolute basis the computed results are $12-17 \%$ low and on a relative basis they are as much as a factor of seven times too low. It is concluded that these kinetic expressions would not match the experimental data regardless of the details of the solid history within the process units.

A simplified kinetic model based on limited data of Watkins 6 yield much better estimates of the carbonate decomposition in the 4TU-Pilot. The computed results on an absolute basis were within five percent of the measured carbonate decomposition levels. Computed carbonate levels in the fines and non-fines exiting the system were essentially equal, in agreement with available 4TU-Pilot data. Finally, the computed results indicate some carbonate decomposition occurs on the pyrolysis side of the system, which is at a temperature of 500-550 C. The amount of carbon dioxide produced from the computed decomposition is in fair agreement with the measured amounts of carbon dioxide in gas produced from the pyrolysis side of the 4TU-Pilot.

\section{References}

1. Cena, R.J. and Thorsness, C.B. (1992). HRS Pilot Retort and Modeling Results, $25^{\text {th }}$ Annual Western Oil Shale Symposium, Golden, Colorado. April 21-22, 1992.

2. Thorsness, C.B. OSP Modeling of Pilot Runs. Lawrence Livermore National Laboratory UCRL-ID-112840, Feb. 3, 1993.

3. Cena, R.J. and Thorsness, C.B. The LLNL 4TU-Pilot Plant for the Study of HotRecycled-Solid Oil Shale Retorting Volume 2. Operating Data. Lawrence Livermore National Laboratory Report in preparation.

4. Jukkola, E.E., Denilauler, A.J., Jensen, J.B., Barnet, W.I, and Murphy,W.I.R. Thermal Decomposition Rates of Carbonates in Oil Shale. Industrial and Engineering Chemistry, Vol 45, No.12, pp. 2711-2714, 1953

5. Lewis, A.E. Lawrence Livermore National Laboratory Oil Shale Project Quarterly Report, July-September 1986. Lawrence Livermore National Laboratory UCID-11698686-3, Rev I, pp 1-8.

6. Watkins, B.E., Morris, C.J, Fields,D., and Thorsness, C.B. Kinetics of Kerogen and Carbonate Mineral Decomposition in Oil Shale in a Laboratory Fluid Bed. Lawrence Livermore National Laboratory UCRL-ID-115385, Nov 1993. 